http://jmscr.igmpublication.org/home/ ISSN (e)-2347-176x ISSN (p) 2455-0450 crossref DOI: https://dx.doi.org/10.18535/jmscr/v8i4.78

\title{
A study on seroprevalence of Rubella IgG antibodies among antenatal women in a tertiary care centre in Kerala
}

\author{
Authors \\ Dr Nita Fazil ${ }^{1}$, Dr Shoba Pillai ${ }^{2}$, Dr Vibi Varghese ${ }^{3}$, Dr J. Lancy ${ }^{4}$ \\ ${ }^{1}$ Assistant Surgeon \\ *Corresponding author \\ Dr J. Lancy \\ Professor of Microbiology GMC, Ernakulam, Kerala, India
}

\begin{abstract}
Rubella is a mild exanthematous fever characterised by transient macular rash that often goes unnoticed. It is of worldwide distribution. However, rubella infection in pregnant females can lead to grave consequences due to its teratogenicity. Rubella vaccine was included in the National Immunisation Programme only in 2017. Before that the vaccine was available in the private sector. Even after 100\% immunisation, there were changing trends in IgG antibody levels in various groups of people. A study was conducted in the department of Microbiology at Government Medical College, Ernakulam to find out the seroprevalence of Rubella IgG antibodies among pregnant women attending the OPD of the Obstetric and Gynaecology department during a period of one year from May 2017 to April 2018 by doing a quantitative ELISA.A total number of 200 blood samples were tested. Majority of the patients were unimmunised (60\%) and the seropositivity was $69.17 \%$ and the seropositivity among immunised women was $39.5 \%$.

Keywords: Rubella, Quantitative ELISA, IgG antibody.
\end{abstract}

\section{Introduction}

Rubella virus is a RNA virus belongs to the family Togaviridae. It produces congenital infections in newborn (Congenital Rubella Syndrome) when Rubella occurs in pregnant women. It can infect the foetus and can lead to serious consequences depending on the period of gestation. Humans are the only known hosts for Rubella. So continuous access to a susceptible population is required for its maintenance. It is endemic in several developing countries.

ELISA is the most common test done because it is relatively cheap and sensitive. ELISA can give qualitative and quantitative detection and estimation of antibody levels and IgM antibodies denote acute infection. IgG antibodies denotes past infection, post vaccination or immunity. According to $\mathrm{WHO}, \mathrm{IgG}$ value $\geq 10 \mathrm{IU} / \mathrm{ml}$ is protective.

\section{Objectives of the Study}

The study was conducted to determine the seroprevalence of Rubella IgG antibodies among pregnant women attending the Obstetric and Gynaecology OPD of Government Medical College, Ernakulam for a period of one year from May 2017 to April 2018 and to assess the factors affecting the levels of Rubella antibody. 


\section{Materials and Methods}

Study Design: Descriptive Cross Sectional Study Study Setting: Department of Microbiology and Department of Obstetrics and Gynaecology, GMC, Ernakulam.

Study Period: $1 / 5 / 2017$ - 30/4/2018 (I year)

Study Population: Pregnant Females

Age Group: 18 years to 40 years

Sampling Technique: Convenient sampling

Exclusion Criteria: Haemolysed sample

Sample Size: 220, calculated using the formula $\mathrm{n}=\mathrm{z}^{2} \mathrm{pq} / \mathrm{d}+10 \%(10 \%$ is the wastage rate $) ; \mathrm{d}$ is the relative precision taken as 10 .

\section{Sample Collection and Processing}

Study population included pregnant females attending Obstetrics outpatient department who were advised routine serological tests or other blood tests by the obstetrician

A written informed consent was taken. The data was collected as per the pre-prepared questionnaire. $3 \mathrm{ml}$ of the venous blood was collected under sterile precautions in a sterile screw capped storage vial to test for Rubella antibodies.

In the serology lab, the blood samples were centrifuged, serum separated and was stored in two aliquots one at a temperature of $4^{\circ} \mathrm{Ceicius}$ and the other at $-20^{\circ} \mathrm{C}$ freezer for future use if any. Tests were conducted within 10 days of sample collection using EUROIMMUNE- Rubella IgG ELISA kits. Tests in duplicate were done for $20 \%$ of the total samples that were tested.

\section{Quantitative ELISA was done using Euroimmune kit}

Procedure: Transfer 100 microlitre of the calibrators, positive and negative controls and diluted patient samples into the individual microplate wells according to the pipetting protocol. Incubate for 30 minutes at room temperature. Empty the wells and subsequently wash three times using 300 microlitre of working strength wash buffer for each wash. In automatic washing, wash the reagent wells three times with 450 microlitre of working strength wash buffer.
Leave the wash buffer in each well for 30 to 60 seconds per washing cycle, then empty the wells. After washing thoroughly dispose of all liquid from the microplate by tapping it on absorbent paper with the openings facing downwards to remove all residual wash buffer. Free positions on the microplate strip should be filled with blank wells of the same plate format as that of the parameter to be investigated. Pipette $100 \mu 1$ of the enzyme conjugate (Peroxidase labelled antihuman $\mathrm{IgG}$ ) into each of the microplate wells. Incubate for 30 minutes at room temperature. Empty the wells and wash as described above.

Pipette $100 \mu 1$ of chromogen substrate solution into each of the microplate wells. Incubate for 15 minutes at room temperature $\left(18-25^{\circ} \mathrm{C}\right)$. Protect from direct sunlight. Pipette $100 \mu 1$ of stop solution into each of the microplate wells in the same order and at the same speed as the chromogen substrate solution was introduced.

Photometric measurement of the colour intensity should be made at a wavelength of $450 \mathrm{~nm}$ and a reference wavelength between $620 \mathrm{~nm}$ and $650 \mathrm{~nm}$ within 30 minutes of adding the stop solution.

\section{Calculation of Results}

Quantitative: The standard curve from which the concentration of antibodies in the patient samples can be taken is obtained by point to point plotting of the extinction values measured for the four calibrators against the corresponding units. If the extinction for a patient sample lies above the value of calibrator $1(200 \mathrm{IU} / \mathrm{ml})$, the result should be reported as "> $>200 \mathrm{IU} / \mathrm{ml}$ ". It is recommended that the sample be retested at a dilution of ex:1:400. The result in IU/ml read from the calibration curve for the sample must then be multiplied by a factor of 4. The upper limit of the reference range of non- infected persons (cut-off value) recommended by Euroimmune is $10 \mathrm{IU} / \mathrm{ml}$. Euroimmune recommends interpreting results as follows:

$<8 \mathrm{IU} / \mathrm{ml}$ : Negative

$>8$ to $<11 \mathrm{IU} / \mathrm{ml}$ : Borderline

$>11 \mathrm{IU} / \mathrm{ml}$ : Positive 
For duplicate determinations, the mean of the two values should be taken. If the two values deviate substantially from one another, EUROIMMUNE recommends to re-test the samples.

\section{Results}

The present study was conducted in the department of Microbiology from $1^{\text {st }}$ of May 2017 to $30^{\text {th }}$ April 2018.A total number of 200 samples were collected from pregnant females attending obstetrics outpatient department during the period. Majority of the population in the study group belongs to the age between 21-30 years (72.5\%). The youngest one from which sample was collected was 18 years and the oldest was 40 years old. The mean age of the participants is 26 years.

Among the pregnant females attended the OPD, $55.5 \%$ were from urban areas and $44.5 \%$ from rural areas. Among the antenatal women from whom samples were collected, $67 \%$ were primi gravida and $33 \%$ were multigravida.

Table 1: Rubella IgG value vs Age groups

\begin{tabular}{|l|c|c|c|}
\hline Age group & Mean & Number & SD \\
\hline $18-20$ & 72.702 & 16 & 64.243 \\
\hline $21-30$ & 65.012 & 145 & 61.947 \\
\hline $31-40$ & 68.994 & 39 & 63.753 \\
\hline
\end{tabular}

Table 2: Rubella IgG value vs Residence category

\begin{tabular}{|l|c|c|c|}
\hline Residence & Mean & Number & SD \\
\hline Rural & 69.869 & 89 & 66.099 \\
\hline Urban & 63.608 & 111 & 59.061 \\
\hline
\end{tabular}

Table 3: Rubella IgG value vs Obstetric score

\begin{tabular}{|l|c|c|c|}
\hline Obstetric score & Mean & Number & SD \\
\hline Primi gravida & 64.448 & 66 & 63.875 \\
\hline Multi gravida & 67.352 & 134 & 61.592 \\
\hline
\end{tabular}

Table 4: Rubella IgG value vs Gestational age

\begin{tabular}{|l|c|c|c|}
\hline Gestational age & Mean & Number & SD \\
\hline $1^{\text {st }}$ trimester & 63.397 & 53 & 59.824 \\
\hline $2^{\text {nd }}$ trimester & 66.491 & 53 & 61.003 \\
\hline $3^{\text {rd }}$ trimester & 68.023 & 94 & 64.734 \\
\hline
\end{tabular}

Table 5: Rubella IgG value vs Bad Obstetric History

\begin{tabular}{|l|c|c|c|}
\hline BOH & Mean & Number & SD \\
\hline Present & 94.814 & 6 & 70.595 \\
\hline Absent & 65.515 & 194 & 61.929 \\
\hline
\end{tabular}

Table 6: Rubella IgG value vs Immunization status

\begin{tabular}{|l|c|c|c|}
\hline Immunization status & Mean & Number & SD \\
\hline Immunized & 106.654 & 80 & 59.222 \\
\hline Unimmunized & 39.554 & 120 & 48.240 \\
\hline
\end{tabular}

Immunisation status had a statistically significant association with Rubella antibody levels. None of the other factors were found to have a statistically significant association with Rubella IgG value.

\section{Discussion}

A total number of 200 blood samples were collected from pregnant females in Government Medical College, Ernakulam from May $1^{\text {st }} 2017$ to $30^{\text {th }}$ April 2018.

\section{Age distribution}

Majority of the population in the study group belongs to the age between 21-30 years (72.5\%).No statistically significant association was found between age and antibody levels. Similar studies by Zanga et al also shows no significant association between age and antibody levels. Studies from Uttar Pradesh (UP), Amritsar and Bengladesh showed higher prevalence among 20 - 25 age $(88.2 \%), 26-35$ years $(77.2 \%)$ and $25-$ 30 year $(77.8 \%)$ respectively compared to other age without any statistical significance. Studies at Kozhikode (Kerala) showed high positivity $95.7 \%$ in the 20-30 year group but it was not statistically significant.

\section{Studies from Western Countries}

A study in Turkey (between 2014-16) have reported that among pregnant women seroprevalence of Rubella IgG antibodies was 93.5\%.Rubella vaccine was included in National immunization schedule from 2006.The study included 7513 pregnant women with age ranging from 18-45 years with a mean age of 30.7 years. Information on Rubella vaccination was not collected so the effect of vaccination on seropositivity rate was not determined. The study didn't look into the effect of other factors that can affect Rubella IgG antibody levels. 
Canada achieved elimination of both Rubella and CRS by 2005. Rubella vaccine was introduced since 1983. The study included 1928 pregnant women with age ranging from 18-48 years during 2008-2011. Seropositivity was $87.6 \%$.According to Nicolas et al immigrants and lower education status to be considered as risk factors for Rubella susceptibility.

A study from Northern Mexico (8 months study) 2013.279 pregnant women 15-43 years, seropositive $97.1 \%$.Vaccination was started from 1998.

A study in Northern Italy included 2255 pregnant women, a two year study from 2008-2010.8\% were seronegative. Vaccines were introduced from 1970s.

A study from Shiraz, Southern Iran during 20112012(3 months study), including 175 pregnant women. The agr ranged from16-42. Seroprevalence was $97 \%$.

A study from Kuwait between 2012-2013(3 months study), included 4062 pregnant women. Rubella vaccines were introduced since 30 years. Seroprevalence was $88.4 \%$, comparable to 85 $90 \%$ in European women in Turkey and in Australia. In Nigeria 54.1\%, Srilanka 76\%.

A study in Malaysia during June to October 2005 included 500 pregnant women with age ranging from 16-42 years. Mean age was 27 years. Seroprevalence was $88.6 \%$.Almost half $(49.2 \%)$ were primigravida. The prevalence of Rubella susceptibility was $11.4 \%$. Most susceptible. In Malaysia the Rubella vaccination programme was started from 1988.

\section{Studies in Kerala}

Study at Kozhikkode on 100 pregnant women age ranging from 18-33.The mean $\mathrm{IgG}$ value was 192.45+/-102.58 IU. Seroprevalence was $94.3 \%$. A similar study done in Kerala during 2003-2006 showed an $\operatorname{IgG}$ positivity in $65.7 \%$ and a susceptible population of $34.3 \%$; which is higher than elsewhere in India. Similar study by Shanmugham et al in 1982 seroprevalence was $74 \%$.

\section{Conclusion}

- The study on "Seroprevalence of Rubella $\mathrm{IgG}$ antibodies among pregnant females in a tertiary care centre" was conducted in the Department of Microbiology at GMC, Ernakulam during a period of one year from $1 / 5 / 2017$ to $30 / 4 / 2018$.

- A total number of 200 blood samples were collected under sterile precautions from pregnant females who attended the outpatient department of Obstetrics and Gynaecology during the above period. ELISA was performed with all the samples to detect Rubella IgG antibodies in the 24 hours serology laboratory at Government Medical College Hospital.

- Among the samples tested, 161 were positive $(80.5 \%)$ and 39 were negative (19.5\%). Mean antibody levels of the study population is $66.394 \mathrm{IU} / \mathrm{ml}$. Majority of the antenatal women $(72.5 \%)$ belonged to the age group between 21-30 years with a mean antibody value of $65.012 \mathrm{IU} / \mathrm{ml}$. Mean age of the study population is 26 years, with lowest age group of 18 years.

- $55.5 \%$ from urban areas with a mean antibody titre of $63.608 \mathrm{IU} / \mathrm{ml}$ and $44.5 \%$ of the study population were from rural areas with a mean antibody value of $69.869 \mathrm{IU} / \mathrm{ml}$.

- $67 \%$ were multigravidae with a mean antibody value of $67.352 \mathrm{IU} / \mathrm{ml}$ and $33 \%$ of the study population were primi with a mean antibody value of $64.448 \mathrm{IU} / \mathrm{ml}$.

- $26.5 \%$ were in first trimester with a mean antibody value of $63.397 \mathrm{IU} / \mathrm{ml}, 26.5 \%$ were in second trimester with a mean antibody value of $66.491 \mathrm{IU} / \mathrm{ml}$ and $47 \%$ were in the third trimester with a mean antibody value of $68.029 \mathrm{IU} / \mathrm{ml}$.

- Only 3\% had bad obstetric history with a mean antibody value of $94.814 \mathrm{IU} / \mathrm{ml}$.

- $40 \%$ were immunised with a mean antibody value of $106.654 \mathrm{IU} / \mathrm{ml}$ and $60 \%$ 
of unimmunised had a mean antibody value of $39.555 \mathrm{IU} / \mathrm{ml}$.

- Majority of the participants are unimmunized (60\%), and the seropositivity among them is $(69.17 \%)$.

- In our study $19.5 \%$ are seronegative which emphasizes the need for catch up immunization programmes. The number of seronegative or susceptible in our study is $19.5 \%$ and is quite significant as according to WHO even $10 \%$ can lead to CRS outbreaks especially among unimmunized individuals. So immunization should be mandatory and to be made available freely in two doses one in paediatric age group followed by second dose at early teens. Following vaccination Seroconversion should be confirmed and to be followed atleast 10 yearly upto the age of 30 years to ensure protection. Studies should involve the immigrants also as we strengthen the immunization policies and antibody screening here.

- The present study shows high seropositivity of $80.5 \%$ which suggests the need for the routine screening of Rubella IgG antibodies among antenatal women. To confirm the data it is necessary to conduct further studies in which screening tests should be performed in large populations.

\section{Acknowledgement}

I am grateful to Dr. Mercy John Idikkula, previous Professor and HOD, Department of Microbiology, GMC, Ernakulam for her guidance and support in the beginning of the study.

Financial support and sponsorship - NIL Conflicts of interest - NIL

\section{References}

1. Dewan P, Gupta P.Burden of Congenital Rubella Syndrome (CRS) in India: A systematic Review Indian Pediatr; May 2012;49(5):377-99.
2. Baschirotto, P.T, Krieger M.A and Foti L. Preliminary multiplex microaaray IgG immunoassay for the diagnosis of Toxoplasmosis and Rubella. Mem Inst Oswaldo Cruz, Jun 2017;112(6):428-436.

3. Lin C.C, Yang C.Y, Shih Y.L. et al. Persistance and Titer Changes of Rubella Virus Antibodies in Primiparous Women who had been vaccinated with strain RA 27/3 in Junior High School. Clin Vaccine Immune. Dec 2011; 19(1):1-4.

4. Mangala Prasad .V, Willows S.D, Fokine.A.et al. Rubella virus capsid protein structure and its role in virus assembly and infection. Proceedings of the National Academy of Sciences of the United States of America, Dec 2013;110 (50):20105-20110.

5. Abernathy.E, Chen.M, Bera.J, et al. Analysis of whole genome sequences of 16 strains of Rubella virus from the United States, 1961-2009.Virology journal, Jan 2013; 10(1):10-32.

6. WHO. Standardisation of the nomenclature for genetic characyeristics of wild type Rubella viruses.2005; Wkl Epideol Rec 88, 337-43.

7. WHO.WHO Strategic plan for measles elimination and Rubella and Congenital Rubella Syndrome Control in the South East Asia Region 2014-2020.

8. WHO.WHO-recommended surveillance standard of Rubella and Congenital Rubella Syndrome. 2014.

9. Brooks F.G, Butel J.S, Morse S.A, Melnick J.L, Jawetz E, Adelberg E.A (2004). Rubella virus. In: Medical Microbiology, $23^{\text {rd }}$ (edn).Chapter 40:566-568.

10. Zhu. Z, Rivailler. P et al. Evolutionary analysis of Rubella viruses in mainland China during 2010-2012: endemic circulation of genotype $1 \mathrm{E}$ and introductions of genotype 2B.Nature Research Journal. Jan 2015.Scientific Reports 5, Article number:7999. 
11. Wandinger $\mathrm{k}, \quad$ Saschenbecker $\mathrm{S}$, Stainhagen $\mathrm{K}$ et al.Diagnosis of recent primary Rubella virus infections: significance of glycoprotein based $\operatorname{IgM}$ serology, IgG avidity and immunoblot analysis. Journal of Virological Methods, Jun 2011;174(1-2):85-93.

12. Gupta E, Dar L and Broor. S. Seroprevalence of Rubella in pregnant women in Delhi, India. The Indian Journal of Medical Research, 2006;123(6),833-5.

13. Control and prevention of Rubella: evaluation and management of suspected outbreaks, Rubella in pregnant women and surveillance for Congenital Rubella Syndrome. MMWR Morb Mortal Wkly Rep 2001; 50:1-23.

14. Zanga J, Mbanzulu M.K, Kabasele A.F et al. Rubella seroprevalence and real time PCR detection of RUBV among Congolese pregnant women.BMC Infectious Diseases, April 2017;17(1):1.

15. Singla N, Jindal N, Aggarwal A. The seroepidemiology of Rubella in Amritsar (Punjab).IJMM, 2004; 22(1):61-63

16. Padmaja M, Radhakrishna P.M, Sam J.V. Seroprevalence of immunity to Rubella in pregnant women. The National Medical Journal of India.2010;23(4):248-9. 